\title{
A Probabilistic Approach for Optimizing Inspection, Monitoring, and Maintenance Actions Against Fatigue of Critical Ship Details
}

\author{
Mohamed Soliman $^{1}$, Dan M. Frangopol ${ }^{2, *}$, Alysson Mondoro ${ }^{3}$
}

\begin{abstract}
Fatigue is one of the main deteriorating mechanisms that affect the safety and reliability of ship structures. Fatigue cracks can appear at various locations along the ship structure and may occur at early stages in the service life of a ship. Inspection, monitoring and/or repair actions are applied to prevent sudden failures of damaged structural components and their associated consequences. However, these actions increase the operational cost of the ship and should be effectively planned during its service life. Due to the presence of significant uncertainties associated with crack initiation and propagation, the planning of such actions should be performed probabilistically. In this paper, a probabilistic approach for inspection, monitoring, and maintenance optimization for ship details under fatigue effects is proposed. Based on the stress profile and the crack geometry at the damaged location, intervention times and types are determined by solving an optimization problem which simultaneously minimizes the life-cycle cost, maximizes the expected service life, and minimizes the expected maintenance delay over the life-cycle. The life-cycle cost includes the cost of inspection, monitoring, and maintenance actions, as well as the cost of failure of the detail. The proposed approach is applied to a side shell detail of a steel ship.
\end{abstract}

Keywords: fatigue, failure, inspection, maintenance, life-cycle cost, optimization

\footnotetext{
${ }^{1}$ Assistant Professor, School of Civil and Environmental Engineering, College of Engineering, Architecture and Technology, Oklahoma State University, 207 Engineering South, Stillwater, OK 74078-5033 mohamed.soliman@okstate.edu

${ }^{2}$ Professor and the Fazlur R. Khan Endowed Chair of Structural Engineering and Architecture, Department of Civil and Environmental Engineering, ATLSS Engineering Research Center, Lehigh University, 117 ATLSS Dr., Bethlehem, PA 18015-4729, dan.frangopol@1ehigh.edu.

${ }^{3}$ Graduate Research Assistant, Department of Civil and Environmental Engineering, ATLSS Engineering Research Center, Lehigh University, 117 ATLSS Dr., Bethlehem, PA 18015-4729, alm312@,lehigh.edu

${ }^{*}$ Corresponding Author, dan.frangopol@lehigh.edu.
} 


\section{Introduction}

Ship structures are subjected to various environmental and mechanical stressors through their service life. These stressors may induce several types of structural deterioration including fatigue damage [1]. Fatigue is defined as the process of damage accumulation resulting from repeated load fluctuations. The damage may occur around regions of high stress concentrations where there are existing flaws in the material due to welding and/or fabrication. Over a certain number of stress fluctuations, the initiation and propagation of cracks may occur, and, eventually, cause fracture in the component [2]. Inspection and monitoring actions are performed to assist in fatigue damage diagnosis and prognosis [3]. Additionally, maintenance and repairs can be performed to improve the structural performance and extend the service life [4].

However, these actions significantly impact the total life-cycle cost of a structure, especially if their application requires setting the structure out of service for a certain period of time. Moreover, since fatigue damage may lead to catastrophic failures [5], delayed maintenance can endanger the serviceability and survival of a structure. Therefore, minimizing the maintenance delay, defined in general as the time lag between the damage occurrence and the application of the maintenance, may require additional inspections and maintenance actions to be performed yielding a higher life-cycle cost. Thus, interventions must be rationally planned along the service life of a structure to maintain an optimal balance between the service life, life-cycle cost, and maintenance delay. This task represents a major challenge for infrastructure managers due to the presence of various uncertainties associated with the performance prediction, damage initiation and propagation, inspection and monitoring outcomes, and the effect of maintenance on 
the structural performance. Therefore, the optimization of these interventions must be performed within a probabilistic framework.

Several approaches have been proposed for the probabilistic inspection and/or maintenance planning for fatigue critical structures [6-9]. In these studies, probabilistic performance indicators such as the probabilistic damage level (e.g., crack size) or reliability index have been used. The main outcomes of such studies include the optimum non-destructive inspection (NDI) times and types, as well as, the ideal maintenance times. In addition to these outcomes, Kim et al. [10] and Kwon and Frangopol [11] provide the optimum maintenance types for fatigue critical structures under uncertainty.

The use of monitoring systems with automated ability to detect fatigue crack growth has emerged as an alternative to traditional NDI methods. These systems rely on installing sensors that continuously monitor and record the structural response or emissions and attempt to identify and localize the damage based on the recorded data. Thus, they can detect the damage with minimal disturbance to the operational schedule of the ship. An example of such systems is the acoustic emission (AE) monitoring for steel and aluminum structures [12-14]. However, the use of long-term monitoring may impose a high life-cycle cost associated with the continuous need to transfer and process acquired data, in addition to the maintenance of the monitoring system itself.

As a result, several studies focused on optimizing the inspection and monitoring activities along the service life of a structure. Kim and Frangopol [8] proposed an approach for the inspection and monitoring optimization of structures under fatigue effects. The approach was focused on minimizing the expected damage detection delay and the inspection and monitoring cost. Orcesi and Frangopol [15] proposed another approach in which the optimization problem 
was formulated to find the best monitoring plan to minimize the error in the collected data that arises from interrupting the monitoring activities throughout the service life. Minimizing the monitoring cost was also included as an objective. Although these studies performed the scheduling for inspection and monitoring actions, maintenance and repair planning was not included; this limits their applicability and precludes them from being integrated into a method to extend service life.

This paper proposes a comprehensive probabilistic framework for optimizing the inspection, monitoring, and maintenance activities during the service life of fatigue critical structures with emphasis on ship details. A multi-objective optimization problem is formulated and solved to simultaneously minimize the total life-cycle cost, maximize the expected service life, and minimize the expected maintenance delay. The life-cycle cost includes the costs associated with inspection, monitoring, and maintenance activities, as well as the expected failure cost. This last cost is computed by combining the monetary loss resulting from structural failure and the time-based probability of failure defined in terms of the required service life and the probability density function (PDF) of the service life extended through the application of maintenance actions.

The proposed approach contributes to the life-cycle management problem by: (a) being able to simultaneously schedule inspection, monitoring, and maintenance activities, (b) integrating the probability of failure and the failure cost into the life-cycle cost formulation, and (c) providing the ability to minimize the delay associated with the application of maintenance actions along the service life. The results of this approach are the optimum inspection times, monitoring times and durations, and critical crack size for applying maintenance. This approach provides the ability to use the measured damage level during inspection and monitoring actions 
to identify the need for maintenance. Accordingly, the resulting management plans allow for an effective and reliable decision making process. The proposed approach is illustrated on a ship detail subjected to fatigue.

\section{Time-based performance and probability of failure}

Fatigue cracking represents a major threat to the safety and reliability of ship structures. Fatigue problems manifest themselves in ships due to the nature of fluctuating sea loads and the large number of welded connections where stress concentrations may arise. Despite the existence of several design codes and regulations to assist in the fatigue design and assessment, fatigue cracking occurs in various types of ships [16]. Fatigue cracking is a highly uncertain phenomenon which justifies the use of probabilistic methodologies to assess the fatigue reliability and service life [17].

Traditionally, the fatigue behavior of ship structures is assessed through either the $S-N$ (i.e., stress-life) approach or the methodologies based on fracture mechanics. The $S-N$ approach is widely used by the codes and regulations for fatigue design and assessment [18-20]. However, it cannot be used to study the crack condition at a damaged detail. For ship details, linear elastic fracture mechanics can be used for studying the crack growth [2]. In this paper, the fatigue performance is measured in terms of the probabilistic damage level which is considered herein as the time-dependent crack size obtained by employing Paris' equation. This equation relates the crack growth rate to the range of the stress intensity factor and is given by [21] 


$$
\frac{d a}{d N}=C \cdot(\Delta K)^{m}
$$

where $a$ is the crack size, $N$ is the number of cycles, $\Delta K$ represents the range of the stress intensity factor, while $C$ and $m$ are material parameters. The range of the stress intensity factor can be expressed as

$$
\Delta K=K(a) \cdot S_{r e} \cdot \sqrt{\pi a}
$$

where $S_{r e}$ is the equivalent constant-amplitude stress range and $K(a)$ is the generalized stress intensity factor which depends on the crack orientation and shape. This factor takes into account the effects of the elliptical crack shape, free surface, finite width (or thickness), and non-uniform stress acting on the crack. Detailed empirical and exact solutions for $K(a)$ can be found in [5] and [22].

Based on Equations (1) and (2), the cumulative number of cycles required for the crack to grow from an initial size of $a_{o}$ to a size of $a_{t}$ is

$$
N=\frac{1}{C \cdot S_{r e}^{m}} \cdot \int_{a_{o}}^{a_{t}} \frac{1}{(K(a) \cdot \sqrt{\pi a})^{m}} d a
$$

Considering the annual average number of cycles $N_{\text {avg }}$, the number of years $t$ associated with a crack growth from $a_{o}$ to a size of $a_{t}$ is

$$
t=\frac{1}{N_{a v g} \cdot C \cdot S_{r e}^{m}} \cdot \int_{a_{o}}^{a_{t}} \frac{1}{(K(a) \cdot \sqrt{\pi a})^{m}} d a
$$

By considering $a_{t}$ to be equal to the critical crack size $a_{f}$, the time to failure $T$ (i.e., service life) of the detail can be obtained. Since the initial crack size $a_{o}$, crack growth parameter $C$, exponent 
$m$, stress range $S_{r e}$, and the average annual number of cycles $N_{\text {avg }}$ are random, Monte Carlo simulation is used to draw samples from the time to failure $T$.

The PDF of $T, f_{T}(t)$, can be then obtained through an appropriate distribution fitting process such as the maximum likelihood method [23]. For small time interval $\Delta t$ and a given time $t$, this PDF provides the probability that the failure will occur between the time $t$ and $(t+\Delta t)$. Therefore, it has the following probabilistic interpretation [24]

$$
f_{T}(t)=\frac{P(t \leq T \leq(t+\Delta t))}{\Delta t}
$$

where $P(\cdot)$ represents the probability of occurrence of the event between parentheses. Based on the simulated $\mathrm{PDF}, f_{T}(t)$, the cumulative probability of failure $(\mathrm{CDF}), F_{T}(t)$, representing the probability that the time to failure $T$ (i.e., service life) of a component is less than $t$, is calculated as

$$
F_{T}(t)=P(T \leq t)=\int_{0}^{t} f_{T}(u) d u
$$

The simulation process and the resulting PDF and CDF of the time to failure are shown schematically in Figure 1.

In order to compute the probability of failure and the expected cost of failure, a failure event must be defined. Several definitions for failure can be found in literature. For instance, reliability theory states that the failure occurs when the demand on the structure exceeds its capacity [25]. Chung et al. [6], Kim and Frangopol [8], and Soliman and Frangopol [26] defined the probability of failure as the probability that the crack will reach its critical size without being 
detected by the inspection plan. In this study, the time-based probability of failure is computed based on the CDF, $F_{T}(t)$, of the service life $T$, which can be extended through the application of maintenance actions. If a specific service life $t^{*}$ is required, the probability of failure $P_{f}$, given as the probability that the critical crack size will be reached before $t^{*}$, is computed as $P_{f}=P\left(T \leq t^{*}\right)=F_{T}\left(t^{*}\right)$. The application of maintenance actions will change the PDF and CDF of the service life in the manner shown in Figure 1 and, consequently, will change the probability of failure. $P_{f}$ is later incorporated into the optimization scheme presented in this paper.

\section{Non-destructive fatigue inspection and monitoring}

Fatigue inspection of ships is an essential process to ensure structural safety and reliability. Visual inspection and ultrasonic gauging are the most widely used method for fatigue inspection [27]. The results of these inspection methods may vary according to factors including experience and training of the inspector, weather and lighting, coating and cleanliness, and accessibility of the details. A comprehensive discussion of these factors can be found in [27]. Experience from bridge inspection shows that even during in-depth visual inspection, many of existing cracks can be missed by the inspectors [28] which justifies the use of other NDI techniques.

Among the available NDI techniques, the liquid penetrant, ultrasonic, and magnetic particle inspection methods are widely used for fatigue crack detection. The choice of the appropriate inspection methods depends on the crack type. For example, the liquid penetrant method is more appropriate for surface cracks, whereas the ultrasonic inspection (UI) can detect small and embedded cracks. However, UI requires considerable experience for interpreting the results and is generally more expensive [29]. Although these methodologies provide sufficient detection capabilities, they generally require the location of the crack to be known a priori, which 
may not always be feasible. Additionally, given the large scale of a ship structure and the number of locations that should be inspected, these NDI methodologies may require a long time to be applied to all the critical locations. Moreover, a detailed inspection may require the dry docking of the ship, thus, incurring large economic consequences.

As a result, scientific communities and inspection agencies shifted their focus towards developing monitoring methodologies which can provide automated damage detection, quantification, and localization with minimal interruption to the service schedule of the ship. Examples of these methodologies are the AE method [12] and the ultrasonic guided waves [30] technique. Although these methodologies may have a lower ability in detecting and quantifying the crack size when compared to other methodologies, their use can significantly reduce the inspection time and provide the ability to monitor the damage propagation in real-time. Therefore, the choice of the most appropriate inspection and/or monitoring method depends on multiple variables including the cost, detection ability of the used method with respect to the growing defect, and the need for service interruption, among others. Accordingly, as proposed in this paper, this choice can be made by solving an optimization problem with the inspection and monitoring times and types as its design variables.

\section{Probability of damage detection}

The probability of damage detection ( $\mathrm{PoD}$ ) has been widely used to assess the capacity of the inspection method to detect cracks. This probability is defined as the probability that an existing crack with a specific size will be detected using a given inspection method [6]. Additionally, the PoD has been used as an indicator of the quality of inspection methods which can be given by the probability of detecting a specific crack size or the minimum detectable crack size for the 
inspection method [8]. The PoD has been successfully used for the probabilistic inspection optimization for civil, marine, and aerospace structures [6, 31, 32].

Several forms for the PoD function exist such as the shifted exponential, logistic curve, and the lognormal CDF; the latter is adopted in this paper. The lognormal PoD function is given as [33]

$$
\begin{array}{ll}
P o D=0 & \text { for } 0 \leq a \leq a_{\text {min }} \\
P o D=1-\Phi\left[\frac{\ln (a)-\alpha}{\beta}\right] & \text { for } a>a_{\text {min }}
\end{array}
$$

where $\Phi[\cdot]$ denotes the standard normal CDF, $a$ is the crack size, $a_{\min }$ is the minimum detectable crack size, and $\alpha$ and $\beta$ are the PoD function parameters and they depend on the quality of inspection methods.

For scheduling monitoring activities, recent studies have also shown that the PoD functions can be used with monitoring methods such as the AE technique. Although the typical procedure when using AE is to determine the flaw size by another NDI method, such as the ultrasonic inspection, Pollock [34,35] shows that it is possible to obtain the crack size by using the AE monitoring and that the probability of detecting a certain crack size increases with the increase in the monitoring duration. Hence, in this paper, a time-dependent PoD model for monitoring is considered as shown in Figure 2 and is expressed as

$$
\begin{array}{ll}
P o D=0 & \text { for } 0 \leq a \leq a_{\mathrm{min}} \\
P o D=1-\Phi\left[\frac{\ln (a)-\alpha}{\beta}\right] \cdot R_{t_{m d}} & \text { for } a>a_{\min }
\end{array}
$$

where $R_{t_{m d}}$ is a reduction factor depending on the monitoring duration $t_{m d}$. 


\section{Optimum inspection, monitoring, and maintenance planning framework}

Life-cycle interventions (i.e., inspection, monitoring, and maintenance) help maintain the reliability of a structure above the acceptable threshold and ensure that the required service life will be achieved. However, these interventions significantly affect the life-cycle cost of a ship. On the other hand, fatigue cracks may cause catastrophic failures, which will induce further costs. Reducing the risk of sudden failures due to fatigue cracking can be achieved by minimizing the maintenance delay. However, this may require more and closely spaced inspection and maintenance actions along the service life, which have adverse effects on the lifecycle cost. Therefore, to achieve optimum balance in the life-cycle management, optimal tradeoffs between the expected service life, life-cycle cost, and the maintenance delay must be obtained while considering various uncertainties associated with the problem.

In order to evaluate these three aspects (i.e., the expected service life, life-cycle cost, and the maintenance delay) associated with a given management plan, the event tree model, shown in Figure 3 for one intervention, is adopted. In this model, the set of possible events that may occur at a certain inspection or monitoring action can be represented by the different branches of the

event tree. Each of these branches has a probability of occurrence $P\left(B_{k}\right)$ where $k$ is the branch number. As shown in Figure 3, if the inspection or monitoring is performed after the initial service life (i.e., $t_{1}>T^{o}$, where $t_{1}$ is the first intervention time and $T^{o}$ is the initial service life without maintenance), no further maintenance actions are performed. After an inspection or monitoring, if damage is detected, an in-depth inspection is performed to assess the degree of 
damage. This two-step inspection plan is adopted to minimize the probability of repairing a crack that does not exist [10].

Based on the measured degree of damage, maintenance will be performed if the crack size is larger than a crack size threshold $a_{r}$. It is assumed that during maintenance actions, a repair, which restores the performance of the detail to its initial condition, is performed. If the crack size is smaller than $a_{r}$, repair is not performed until the next scheduled inspection or monitoring action. Based on this model, the probability of occurrence of each branch can be found as shown in Figure 3 for one inspection. The probabilities $P_{t_{i}}(X)$ and $P_{t_{i}}(Y)$ in Figure 3 represent the probability that the intervention performed at $t_{i}$ is executed before and after the initial service life, respectively. $P_{t_{i}}(D)$ and $P_{t_{i}}(N D)$ are the respective probabilities of detecting and not detecting the crack at $t_{i}$, and $P_{t_{i}}(R)$ and $P_{t_{i}}(N R)$ are, respectively, the probabilities of repairing and not repairing the crack at the same time.

\subsection{Expected service life}

The computed service life will depend on the probabilities of occurrence of the branches in the event tree model. For branches $\mathrm{B}_{1}, \mathrm{~B}_{3}$, and $\mathrm{B}_{4}$, no repair is performed and the service life associated with these branches will be equal to the initial service life $T^{o}$. For branch $\mathrm{B}_{2}$, since repair is performed, the service life will be extended by an amount $T^{r}$. Therefore, the service life associated with branch $\mathrm{B}_{2}$ is

$$
T_{2}=t_{1}+T^{r}
$$


where $t_{1}$ is the time of application of the first inspection or monitoring action, and $T^{r}$ is the service life extension after repair considered to be equal to $T^{o}$. Accordingly, the expected service life is

$$
E[T]=\sum_{k=1}^{N_{b}} P\left(\mathrm{~B}_{k}\right) \cdot T_{k}
$$

where $N_{b}$ is the total number of branches and $T_{k}$ is the service life associated with the $k$-th branch. Similarly, when more than one inspection or monitoring action is performed, the probability of branch occurrences can be found and the expected service life can be computed.

\subsection{Expected life-cycle cost}

For inspection and maintenance scheduling, it is crucial to consider the cumulative cost of interventions along the service life. The expected life-cycle cost can be found as

$$
E\left[C_{t o t}\right]=\sum_{k=1}^{N_{b}} P\left(\mathrm{~B}_{k}\right) \cdot C_{k}+P_{f} \cdot C_{f}
$$

where $P_{f}$ is the probability of failure computed as shown in Figure $1, C_{f}$ is the monetary loss associated with the failure of the cracked location which depends on the importance of the detail and it increases if the detail is located on a fracture critical member. $C_{k}$ is the total cost associated with branch $k$, obtained by summing inspection and monitoring costs (i.e., $C_{i n s p}$ and $C_{m o n}$, respectively), as well as in-depth inspection and repair costs (i.e., $C_{i n s p, d}$ and $C_{r e p}$, respectively), for the considered branch

$$
C_{k}=C_{i n s p}+C_{m o n}+C_{i n s p, d}+C_{r e p}
$$

in which 


$$
\begin{aligned}
& C_{i n s p}= \begin{cases}0 & \text { for } N_{i n s p}=0 \\
\sum_{l=1}^{N_{\text {insp }}} \frac{C^{(i n s p)}}{\left(1+r_{d}\right)^{t_{i n p p}}} & \text { for } N_{\text {insp }} \geq 1.0\end{cases} \\
& C_{m o n}= \begin{cases}0 & \text { for } N_{m o n}=0 \\
\sum_{m=1}^{N_{m o n}} \frac{C^{(m o n)}}{\left(1+r_{d}\right)^{t_{m o n}^{(m)}}} & \text { for } N_{m o n} \geq 1.0\end{cases} \\
& C_{i n s p, d}= \begin{cases}0 & \text { for } N_{i n s p, d}=0 \\
\sum_{j=1}^{N_{\text {insp }, d}} \frac{C^{(i n s p, d)}}{\left(1+r_{d}\right)^{t_{i n s p, d}^{(j)}}} & \text { for } N_{i n s p, d} \geq 1.0\end{cases} \\
& C_{\text {rep }}= \begin{cases}0 & \text { for } N_{R}=0 \\
\sum_{n=1}^{N_{R}} \frac{C^{(r e p)}}{\left(1+r_{d}\right)^{t_{r e p}^{(n)}}} & \text { for } N_{R} \geq 1.0\end{cases}
\end{aligned}
$$

where $C^{(i n s p)}, C^{(m o n)}, C^{(i n s p, d)}$, and $C^{(r e p)}$ are the costs of a single inspection, monitoring, indepth inspection, and repair action, respectively. $t_{\text {insp }}^{(l)}$ is the $l$-th inspection time, $t_{m o n}^{(m)}$ is the $m$-th monitoring time, $t_{i n s p, d}^{(j)}$ is the $j$-th in-depth inspection time, $t_{r e p}^{(n)}$ is the $n$-th repair time. $N_{\text {insp }}, N_{\text {mon }}$ , $N_{\text {inss, },}$, and $N_{R}$ are, respectively, the number of inspections, monitoring, in-depth inspection, and repair actions associated with the $k$-th branch, and $r_{d}$ is the annual discount rate of money, introduced to convert the future monetary value of inspections and repairs, performed at different times, to the present one.

In general, the cost of inspection consists of direct and indirect components. The direct cost consists of the access, equipment, and operator costs [36]. The access cost covers the 
expenses for accessing and preparing the different locations that need to be inspected. It depends on the ship type and also on the inspection method since several NDI methods require surface preparation. Equipment cost depends mainly on the type of the NDI used in the inspection. For instance, the ultrasonic inspection would require specialized and expensive equipment when compared to the liquid penetrant inspection. The operator cost includes the fees of the inspector, interpretation of the results, and preparation of the inspection report. The indirect cost covers the economic losses associated with the non-operation status of the ship during the time required for performing the inspection. Therefore, this cost will significantly increase if the inspection requires long time to be performed or if it is necessary to remove the ship from service to perform the inspection.

Monitoring the crack size using acoustic emission devices could be characterized by lower indirect cost since the operator is only required to set up the equipment. However, it will have additional running costs as it involves long-term data acquisition, transfer, and interpretation, in addition to maintenance of the monitoring hardware.

\subsection{Expected maintenance delay}

Maintenance delay is defined herein as the average time lags between the damage occurrence and the application of the maintenance actions and between damage occurrence after the repair and the end of the service life. Reducing this delay is crucial for structures subjected to highly random loading such as ships; especially if sudden failures are possible. In the proposed framework, this expected delay is computed as

$$
E[D]=\sum_{k=1}^{N_{b}} P\left(\mathrm{~B}_{k}\right) \cdot D_{k}
$$


where $D_{k}$ is the maintenance delay associated with the $k$-th branch.

If no maintenance is performed (i.e., branches $\mathrm{B}_{1}, \mathrm{~B}_{3}$, and $\mathrm{B}_{4}$ in Figure 3), maintenance delay is computed as

$$
D_{1,3,4}=T^{o}-t_{o c c}
$$

where $t_{o c c}$ is the damage occurrence time. For branch $\mathrm{B}_{2}$, in which maintenance is performed, the maintenance delay is computed assuming that the maintenance will directly follow the inspection action, and takes the form

$$
D_{2}=\frac{\left(t_{1}-t_{o c c}\right)+\left(T^{o}-t_{o c c}\right)}{2}
$$

where $t_{1}$ is the time of the first maintenance. This accounts for both the time lags between the first damage occurrence and the repair action and between the damage occurrence after the repair and the end of the service life. When more than one maintenance action is performed, the average maintenance delay arising from the application of the first maintenance and the subsequent ones is considered.

The formulated event tree model for obtaining the expected service life, life-cycle cost, and maintenance delay associated with each intervention plan is integrated into an optimization process to find the optimum inspection, monitoring, and maintenance plan. A flowchart describing the details of the optimum intervention planning is shown in Figure 4. The process starts with identifying the probabilistic parameters of the damage propagation model and the parameters of the PoD model and the cost associated with the considered inspection and monitoring method. Next, Monte Carlo simulation is performed to find the PDF and CDF of the initial service life. For a given intervention schedule (i.e., inspection and monitoring times and 
monitoring durations) the event tree model shown in Figure 3 can be used to find the expected service life, life-cycle cost, and maintenance delay using Equations (10), (11), and (17), respectively. However, in order to find the optimum intervention schedule, an optimization process which integrates the formulations of the expected service life, life-cycle cost, and maintenance delay is needed. Such an optimization process, with the design variables of the inspection and monitoring times, monitoring durations, and damage threshold for repairs, is implemented in this framework.

\section{Illustrative Example}

The proposed intervention optimization routine is illustrated on a steel ship side shell detail subjected to fatigue. This critical location is shown in Figure 5. The stress fluctuations at this detail are mainly caused by hydrodynamic and wave induced pressures. Equation (4) is used to predict the time-variant crack size assuming the crack growth exponent $m=3.0$. The crack growth coefficient $C$, is considered to follow a lognormal distribution with a mean of $2.3 \times 10^{-12}$ [37], using units of $\mathrm{mm} / \mathrm{cycle}$ for crack growth rate and $\mathrm{N} / \mathrm{mm}^{3 / 2}$ for the stress intensity factor range, and a coefficient of variation (COV) of 0.3 [32]. The initial crack size $a_{o}$ is assumed to follow a lognormal distribution with mean of $0.5 \mathrm{~mm}[6]$ and a COV of 0.1 . The stress range $S_{r e}$ is considered as a random variable following a Weibull distribution [38] with a mean of $20 \mathrm{MPa}$ and $\mathrm{COV}$ of 0.1, and the function $K(a)$ is considered to be constant, $K(a)=1.12$ [39].

The average annual number of cycles $N_{\text {avg }}$ is also considered to follow a lognormal distribution [32] with a mean value of $1.0 \times 10^{6}$ and a COV of 0.1 . The critical crack size is assumed herein to be $50 \mathrm{~mm}$ and the required service life $t^{*}$ is considered 20 years. Monte Carlo simulation with 100,000 samples is next performed to draw samples from the time to failure of 
the detail which is also considered as the initial service life. Figure 6-a shows the histogram of the initial service life $T^{o}$. As shown, the mean value of $T^{o}$ (i.e., time to reach the critical crack size) is 21.1 years with a standard deviation of 11.1 years. Figure 6-b presents the PDF, $f_{T^{o}}(t)$, and the CDF, $F_{T^{o}}(t)$, of the initial service life. These functions are used next to find the optimum intervention schedule for the investigated detail. It is assumed herein that the damage occurs when the crack size reaches $0.5 \mathrm{~mm}$.

\subsection{Optimization of interventions}

In this section, the optimum interventions schedules, including the optimum inspection and/or monitoring times, monitoring durations, and crack size threshold for performing maintenance are obtained. Minimizing the expected life-cycle cost, minimizing expected maintenance delay, and maximizing the service life are considered as optimization objectives. In order to analyze the effect of the different objectives on the optimal solutions, bi-objective optimization problems are first constructed and solved to find the optimum trade-offs between each of the two objectives, and then investigated in a tri-objective problem. In this example, the ultrasonic technique is considered as the inspection method for fatigue crack detection. It should be noted that depending on the site conditions, other methods, such as the magnetic particle inspection, can also be used to inspect such detail.

Additionally, the $\mathrm{AE}$ technique is considered as the crack monitoring methodology. The PoD parameters $\alpha$ and $\beta$ associated with ultrasonic inspection are considered 0.122 and -0.305 , respectively [40]. In this example, three options for the monitoring duration are considered,

namely, one day, one week, and six weeks. Based on [34,35], the parameters $\alpha$ and $\beta$ associated with $\mathrm{AE}$ monitoring for six weeks are 0.801 and -0.491 , while for monitoring periods of one 
week and one day, a reduction factor $R_{t_{m d}}$ of 0.65 and 0.5 , respectively, is applied to the PoD function as shown in Equation (8).

\subsubsection{Optimum Interventions to Maximize Expected Life and Minimize Expected Total Cost}

At this stage, the optimum intervention schedule is obtained as the solution of an optimization problem with the objective of maximizing the expected service life and minimizing the expected total cost of interventions. The problem is formulated as follows

$$
\begin{aligned}
& \text { given } N_{I}, \underline{\mathbf{C}}, \mathbf{P o D} \text {, and } f_{T^{o}}(t) \\
& \text { Find } \mathbf{t}_{i}=\left\{t_{1}, t_{2}, t_{3}, \ldots \ldots \ldots, t_{N_{I}}\right\}, \mathbf{t}_{m d, i}=\left\{t_{m d, 1}, t_{m d, 2}, t_{m d, 3}, \ldots \ldots \ldots, t_{m d, N_{I}}\right\}, a_{r} \\
& \text { such that } t_{i}-t_{i-1} \geq 1.0 \text { year } \\
& \text { to maximize } E[T] \text { and minimize } E\left[C_{t o t}\right]
\end{aligned}
$$

where $\mathbf{t}_{i}$ is a vector consisting of the design variables of intervention times, $\mathbf{t}_{m d, i}$ is a vector consisting of the monitoring durations, $t_{m d, i}$ is the monitoring time associated with the $i$-th intervention and it is equal to zero for the case of inspection, $a_{r}$ is the critical crack size for repair, $N_{I}$ is the number of interventions, $\underline{\mathbf{C}}$ is a vector consisting of the cost of inspection $C^{(i n s p)}$, monitoring $C^{(\text {mon })}$, in-depth inspection $C^{(i n s p, d)}$, repair $C^{(\text {rep })}$, and failure cost $C_{f}$. PoD is a matrix containing the PoD parameters $\alpha$ and $\beta$ associated with the inspection and monitoring.

As indicated by Equation (22), a constraint has been imposed requiring that the time between successive interventions should be at least one year. In some cases, ship operators may have restrictions with respect to the maximum time interval between inspections. These 
restrictions can also be implemented in the form of the constraint given by Equation (22). Based on the problem formulation, maintenance is applied when the detected crack size is $a_{r}$ or larger. The cost of inspection $C^{(i n s p)}$ is considered to be $\$ 5,000$. The monitoring cost is expressed as

$$
C^{(m o n)}=C_{1}^{m o n}+C_{2}^{m o n} \cdot t_{m d}
$$

in which $C_{1}^{\text {mon }}$ is the initial monitoring cost which covers the hardware and installation expenses and $C_{2}^{m o n} \cdot t_{m d}$ is the running monitoring cost which increases with the increase in the monitoring duration. In this example, $C_{1}^{m o n}$ is considered $\$ 15,000$ and $C_{2}^{\text {mon }}$ is zero for monitoring activities lasting for one day and $\$ 1,000 /$ week for monitoring of one and six weeks. The in-depth inspection cost and maintenance cost are assumed to be $\$ 15,000$ and $\$ 50,000$, respectively. The discount rate of money $r_{d}$ is assumed to be zero.

With all the input parameters defined and using the formulation for the expected service life and total cost given by Equations (12)-(16), the bi-objective optimization problem is constructed and solved using the Global Optimization Toolbox provided in version R2013 of MATLAB [41]. A Genetic Algorithm (GA) with a population size equal to 400 and the maximum number of generations set to 300 is adopted to develop the Pareto-optimal solution set provided in Figure 7. It should be noted that, in all problems, convergence occurred before the maximum number of generations were reached. GAs are used in this paper due to the stochastic nature of their search algorithm and the subsequent avoidance of converging to local minima for this type of problems. The provided Pareto-optimal set of solutions represents the optimum trade-offs between the two conflicting objectives. The Pareto-optimal solutions in Figure 7 consist of three Pareto fronts associated with one, two, and three interventions. Each of the 
optimal solution shown in the front has an associated set of information for the optimal intervention times and types and the critical crack size for maintenance.

Four representative solutions are highlighted in Figure 7 and described in detail in Table 1. For instance, Solution A1 specifies ultrasonic inspection to be performed at the year 19.72 with a critical crack size for maintenance of $5.96 \mathrm{~mm}$. This yields an expected service life of 28.99 years and a total cost of $\$ 28,630$. Solution $A 2$, characterized by a higher life-cycle cost and expected service life, specifies inspection to be performed at 15.13 years with a critical crack size for maintenance of $4.23 \mathrm{~mm}$. Therefore, with respect to a given number of interventions, solutions with higher expected cost and service life are associated with a small crack size for maintenance and earlier intervention times. As shown, the four optimal plans (i.e., A1, A2, A3, and A4) presented in Table 1 and Figure 7 specify only ultrasonic inspections to be performed at all interventions. This is due to the high cost considered and the low probability of detection associated with the AE monitoring compared to those of the ultrasonic inspection.

However, if changes occur to the cost structure of the problem, different trends can be obtained. That is, the Pareto-optimal solutions for the expected service life versus the life-cycle cost optimization problem are altered if the cost for ultrasonic inspection is changed to $\$ 15,000$. This may occur if the inspection requires a long time to be performed or if it is necessary to remove the ship from service to perform the inspection. The cost of ultrasonic and AE are now comparable resulting in an implementation of $\mathrm{AE}$ amongst the optimal management plans. Figure 8-a compares the Pareto-optimal solution fronts of the optimization problem with different cost values of the ultrasonic inspection. Three representative solutions B1, B2, and B3 are selected on Figure 8-a and shown in details in Figure 8-b and Table 1. AE monitoring tends to appear later in the intervention plans as the size of fatigue cracks increase and AE is more 
likely to detect them. It should be noted that, when incorporating a large cost of failure into the cost formulation, the Pareto-optimal solution may be affected. Expected failure cost is, therefore, included in the subsequent optimization problems in the formulation of mean life-cycle cost.

\subsubsection{Optimum Interventions to Minimize Expected Maintenance Delay and Minimize Expected Total Cost}

Understanding the joint effect of minimizing the maintenance delay and the life-cycle cost on the optimum intervention plans requires solving a bi-objective optimization problem. Therefore, a second optimization problem is constructed and solved using the same formulation given by Equations (20)-(22) with the objectives of minimizing the expected maintenance delay $E[D]$ and

minimizing the total life-cycle cost $E\left[C_{t o t}\right]$. Using $\$ 15,000$ for the cost of inspection, and the same GA setup as in the previous bi-objective problem, the optimal solution fronts for $N_{I}=3$ are shown in Figure 9 for failure costs $C_{f}=\$ 0$ and $C_{f}=\$ 500,000$. Two representative solutions, C1 and $\mathrm{C} 2$, are chosen from the front associated with $C_{f}=\$ 0$ and shown in Table 2. The management plan associated with $\mathrm{C} 1$ has a low probability of repair (i.e., $P\left(\mathrm{~B}_{2}\right)=$ probability of occurrence of branch $\mathrm{B}_{2}$ in Figure 3) indicated by the large crack size $a_{r}$, and thus a low repair cost which yields a low life-cycle cost. The solution C2 has a lower crack size $a_{r}$ which yields a higher probability of repair and a higher cost.

The optimal front with failure cost of $\$ 500,000$ presented in Figure 9 shows the effect of probability of failure on the optimal solutions. Solutions C3 and C4 are highlighted and presented in Table 2. With the inclusion of the failure cost, it is observed that the repair crack size $a_{r}$ is generally smaller than the case with $C_{f}=\$ 0$. This indicates a higher probability of performing repairs during an intervention. Comparison among solutions on the front associated 
with $C_{f}=\$ 500,000$ shows that the low life-cycle cost indicates interventions performed later in the service life with lower probability of failure (i.e., Solution C3). While C4 represents a solution which minimizes the maintenance delay by scheduling closely spaced interventions with a high probability of repair. However, these solutions yield a higher life-cycle cost due to the high probability of failure since these repairs are performed early in the service life.

\subsubsection{Optimum Interventions to Minimize Expected Maintenance Delay and Maximize Expected Service Life}

A third optimization problem is constructed and solved using the same formulation given by Equations (20)-(22) with the objectives of minimizing the maintenance delay $E[D]$ and maximizing the expected service life $E[T]$. Figure 10 displays the solution fronts for $N_{I}=1$ and 3. As shown, minimizing the maintenance delay conflicts with maximizing the expected service life requiring a bi-objective optimization to find the optimal trade-offs. Solutions D1, D2, and D3 are highlighted in Figure 10 and also shown in Table 2. The formulation of maintenance delay allows the solutions associated with three interventions (i.e., D2), to have lower maintenance delay values than those specifying only a single intervention to be performed (i.e., D1). The

minimal maintenance delay objective drives management plans towards more frequent and closely spaced interventions, which reduces the expected service life. This effect is demonstrated by comparing the management plans associated with D2 and D3. Additionally, as the initial intervention time is delayed, the maintenance delay increases while the extended life also increases. 


\subsubsection{Optimum Interventions to Minimize Expected Maintenance Delay, Minimize Expected total cost, and Maximize Expected Service Life}

It can be seen from the solution of the previous optimization problems that the three objectives are conflicting each other. In order to find the optimal trade-offs among the three objectives, a tri-objective optimization problem is formulated and solved using the same formulation given by Equations (20)-(22) to maximize $E[T]$, minimize $E[D]$, and minimize $E\left[C_{t o t}\right]$. The Paretooptimal solution sets of the problem, which were derived using the same GA parameters as described in section 6.1.1, are shown in Figure 11 for three interventions and cost of failure of $\$ 0$ and $\$ 500,000$. Details of representative solutions from both fronts are shown in Table 3. In both fronts, solutions with minimal maintenance delay correspond to cases where the inspection and repair actions are performed early in life and are closely spaced. This reduces the mean expected life of the structure and precludes optimal solutions with high service life and low life cycle cost. Moreover, in the front associated with $C_{f}=\$ 500,000$, solutions have high life-cycle cost due to the high probability of failure resulting from the application of early maintenance actions.

Based on the results of this tri-objective optimization problem, decision makers can choose the solution which fits the available budgets and operational constraints. For instance, considering the front associated with a $\$ 500,000$ failure cost, for a maximum allowable life-cycle cost of $\$ 250,000$, the optimization problem provides solutions with expected service life ranging from 31.17 to 51.26 years with a corresponding range of 7.68 to 23.5 years in the expected maintenance delay. Subsequently, based on the expected service life and maintenance delay requirements, an optimum management solution can be selected.

In this tri-objective optimization problem, solutions for the case with no failure cost generally have higher crack size for repair which refers to a lower probability of repair (i.e., 
application of maintenance actions). In order to investigate the effect of the cost of failure on the optimal solutions, the optimization problem is solved again with $C_{f}=\$ 100,000$. Figure 12 shows the progression of the probability of failure averaged over the solutions in the Pareto front, as well as the average total probability of repair, $P_{\text {rep }}^{\text {total }}$, for $C_{f}=\$ 0, C_{f}=\$ 100,000$, and $C_{f}=$ $\$ 500,000$. The probability of repair is computed from the event tree model as the sum of the probabilities of performing one, two, and three repairs in the management plan. As shown, as the cost of failure increases, the total probability of repair among the optimum solutions increases while the probability of failure decreases.

\section{Conclusions}

This paper incorporates a probabilistic fatigue crack growth approach into an optimization routine to find optimal intervention plans which simultaneously minimize the expected maintenance delay, minimize expected life-cycle cost, and maximize expected service life. The proposed intervention planning methodology provides the optimum inspection and/or monitoring times, monitoring durations, and the optimum damage level to perform maintenance. Ultrasonic inspections and acoustic emission crack size monitoring are used as the inspection and monitoring techniques, respectively. However, any inspection or monitoring methodology, with a well characterized probability of damage detection, can be included in the proposed approach. The expected life-cycle cost includes the cost of inspection, monitoring, and maintenance actions performed along the service life, as well as the expected cost of failure. Bi-objective optimization problems were formulated and solved to understand the effect of the different optimization objectives on the optimum solutions. In the sequence, a tri-objective problem which provide the optimal trade-offs among the three objectives was solved to achieve the optimal intervention plans. The following conclusions are drawn: 
1. Minimizing the maintenance delay, maximizing the service life, and minimizing the lifecycle cost are conflicting objectives. Minimizing the maintenance delay tends to increase the life-cycle cost. Additionally, maximizing the service life yields higher expected lifecycle cost.

2. Establishing the optimal life-cycle management plans which fulfil the three conflicting objectives can be achieved using the proposed tri-objective optimization approach.

3. For low values of ultrasonic inspection cost compared to that of acoustic emission monitoring, the optimization scheme suggest that only management plans where ultrasonic inspections are performed are optimal. This is also due to the lower probability of damage detection associated with the acoustic emission crack monitoring, However, if the cost of ultrasonic inspection increases due to the additional time required to perform the inspection, solutions with acoustic emission monitoring appear in the optimal solution front.

4. The monetary value associated with the structural failure has a significant effect on the optimum solutions. A higher value yields solutions which have higher overall probability of performing repairs and lower probability of failure.

5. The results of the proposed approach are affected by the changes in the values of the inspection and monitoring costs, as well as by the ability of inspection and monitoring to detect the damage. Therefore, the accurate estimation of these quantities is required to establish the proper life-cycle management plans.

6. This approach can be extended to cover structures with multiple critical fatigue locations. Additionally, it can include other deteriorating mechanisms, such as corrosion and corrosion-induced fatigue and can be applied to other marine and civil structures. 


\section{Acknowledgments}

The support by grants from (a) the National Science Foundation (NSF) Award CMS-0639428, (b) the Commonwealth of Pennsylvania, Department of Community and Economic Development, through the Pennsylvania Infrastructure Technology Alliance (PITA), (c) the U.S. Federal Highway Administration (FHWA) Cooperative Agreement Award DTFH61-07-H00040, (d) the U.S. Office of Naval Research (ONR) Awards Number N00014-08-1-0188 and Number N00014-12-1-0023 and (e) the National Aeronautics and Space Administration (NASA) Award NNX10AJ20G is gratefully acknowledged. The opinions presented in this paper are those of the authors and do not necessarily reflect the views of the sponsoring organizations

\section{References}

[1] Akpan, U.O., Koko, T.S., Ayyub, B., Dunbar, T. E. (2002). Risk assessment of aging ship hull structures in the presence of corrosion and fatigue. Marine Structures, 15(3), 211-231.

[2] Barsom, J.M., and Rolfe, S.T. (1999). Fracture and fatigue control in structures: Applications of fracture mechanics, ASTM International, Woburn, MA.

[3] Moan, T. (2005). Reliability-based management of inspection, maintenance and repair of offshore structures. Structure and Infrastructure Engineering, 1(1), 33-62.

[4] Frangopol, D.M. (2011). Life-cycle performance, management, and optimization of structural systems under uncertainty: Accomplishments and challenges. Structure and Infrastructure Engineering, 7(6), 389-413.

[5] Fisher, J.W. (1984). Fatigue and fracture in steel bridges, case studies, John Willey \& Sons, New York.

[6] Chung, H., Manuel, L., Frank, K. (2006). Optimal inspection scheduling of steel bridges using nondestructive testing techniques. Journal of Bridge Engineering, 11(3), 305-319.

[7] Garbatov, Y., and Guedes Soares, C. (2001). Cost and reliability based strategies for fatigue maintenance planning of floating structures. Reliability Engineering and System Safety, 73(3), 293-301.

[8] Kim, S., and Frangopol, D.M. (2011). Cost-based optimum scheduling of inspection and monitoring for fatigue sensitive structures under uncertainty. Journal of Structural Engineering, 137(11), 1319-1331.

[9] Kwon, K., and Frangopol, D.M. (2012). Fatigue life assessment and lifetime management of aluminum ships using life-cycle optimization. Journal of Ship Research, 56(2), 91-105.

[10] Kim, S., Frangopol, D.M., Soliman, M. (2013). Generalized probabilistic framework for optimum inspection and maintenance planning. Journal of Structural Engineering, 139(3), 435-447. 
[11] Kwon, K., and Frangopol, D.M. (2011). Bridge fatigue assessment and management using reliability-based crack growth and probability of detection models. Probabilistic Engineering Mechanics, 26(3), 471-480.

[12] Wang, G., Lee, M., Serratella, C., Botten, S., Ternowchek, S., Ozevin, D., Thibault, J., Scott, R. (2010). Testing of acoustic emission technology to detect cracks and corrosion in the marine environment. Journal of Ship Production and Design, 26(2), 106-110.

[13] Maslouhi, A. (2011). Fatigue crack growth monitoring in aluminum using acoustic emission and acousto-ultrasonic methods. Structural Control and Health Monitoring, 18(7), 790-806.

[14] Yu, J., Ziehl, P., Zárate, B., and Caicedo, J. (2011). Prediction of fatigue crack growth in steel bridge components using acoustic emission. Journal of Constructional Steel Research, 67(8), 1254-1260.

[15] Orcesi, A., and Frangopol, D.M. (2013). Bridge performance monitoring based on traffic data. Journal of Engineering Mechanics, 139(11), 1508-1520.

[16] Collette, M., and Incecik, A. (2006). An approach for reliability-based fatigue design of welded joints on aluminum high-speed vessels. Journal of Ship Research, 50(1), 85-98.

[17] Kwon, K., Frangopol, D.M., Kim, S. (2013). Fatigue performance assessment and lifetime prediction of high-speed ship structures based on probabilistic lifetime sea loads. Structure and Infrastructure Engineering, 9(2), 102-115.

[18] DNV. (2010). Fatigue methodology of offshore ships, Det Norske Veritas Classification, Høvik, Norway.

[19] Eurocode 3. (2010). Design of steel structures Part 1-9, Fatigue strength, CEN - European committee for Standardisation, Brussels, Belgium.

[20] Eurocode 9. (2009). Design of Aluminium Structures Part 1-3, Additional rules for structures susceptible to fatigue, CEN - European committee for Standardisation, Brussels, Belgium.

[21] Paris, P., and Erdogan, F. (1963). A critical analysis of crack propagation laws. Journal of Fluids Engineering, 85(4), 528-533.

[22] Tada, H., Paris, P.C., Irwin, G. R. (2000). The stress analysis of cracks handbook, 3rd Ed., ASME, New York, NY.

[23] Ang, A.H., and Tang, W. (2007). Probability concepts in engineering: Emphasis on applications to civil and environmental engineering, Second Ed., John Wiley \& Sons, New Jersey.

[24] Leemis, L.M. (1995). Reliability, probabilistic models and statistical methods, Prentice Hall, New Jersey.

[25] Melchers, R.E. (1999). Structural reliability analysis and prediction, 2nd Ed., John Wiley \& Sons Ltd., Chichester, England.

[26] Soliman, M., and Frangopol, D.M. (2014). Life-cycle management of fatigue sensitive structures integrating inspection information. Journal of Infrastructure Systems, 20(2), 04014001 . 
[27] Demsetz, L., Cario, R., Schulte-Strathaus, R. (1996). Inspection of marine structures, Ship Structures Committee Report No. SSC-389, Ship Structures Committee, Washington, D.C.

[28] Moore, M., Phares, B.M., Graybeal, B., Rolander, D., Washer, G. (2001). Reliability of visual inspection for highway bridges, Federal Highway Administration, U.S. Department of Transportation, Washington, DC.

[29] Fisher, J.W., Kulak, G.L., Smith, I.F. (1998). A fatigue primer for structural engineers, National Steel Bridge Alliance, American Institute of Steel Construction, Chicago, IL.

[30] Cho, H. and Lissenden, C.J. (2012). Structural health monitoring of fatigue crack growth in plate structures with ultrasonic guided waves. Structural Health Monitoring, 11(4), 393404.

[31] Kale, A. A., and Haftka, R.T. (2008). Tradeoff of weight and inspection cost in reliabilitybased structural optimization. Journal of Aircraft, 45(1), 77-85.

[32] Kim, S., and Frangopol, D.M. (2011). Optimum inspection planning for minimizing fatigue damage detection delay of ship hull structures. International Journal of Fatigue, 33(3), 448459.

[33] Crawshaw, J., and Chambers, J. (1984). A concise course in A-level statistics, Stanley Thornes Publishers, Cheltenham, U.K.

[34] Pollock, A. (2007). Probability of detection for acoustic emission. Journal of Acoustic Emission, 25, 231-237.

[35] Pollock, A. (2010). A POD model for acoustic emission-discussion and status. CP1211 In Review of Progress in Quantitative Nondestructive Evaluation, Vol. 209, eds. D.O. Thompson and D.E. Chimenti, AIP Publishing, Melville, NY, 1927-1933.

[36] Soliman, M., Frangopol, D.M., Kim, S. (2013). Probabilistic optimum inspection planning of steel bridges with multiple fatigue sensitive details. Engineering Structures, 49(0), 9961006.

[37] British Standards Institution (BSI). (2005). Guidance on methods for assessing the acceptability of flaws in fusion welded structures. BS7910, London.

[38] Kim, S., and Frangopol, D.M. (2012). Probabilistic bicriterion optimum inspection/monitoring planning: Application to naval ships and bridges under fatigue. Structure and Infrastructure Engineering, 8(10), 912-927.

[39] Guedes Soares, C., and Garbatov, Y. (1999). Reliability based fatigue design of maintained welded joints in the side shell of tankers. European Structural Integrity Society, Volume $23,13-28$.

[40] Forsyth, D., and Fahr, A. (1998). An evaluation of probability of detection statistics. Proc., RTO-AVT Workshop on Airframe Inspection Reliability under Field/Depot Conditions, NATO Research and Technology Organization, Neuilly-Sur-Seine, Cedex, France.

[41] MathWorks (2013). Global optimization toolbox 3.2.2 user's guide, The MathWorks Inc., Natick, MA. 
Table 1. Design variables and objective function values associated with the optimum solutions shown in Figures 7 and 8

\begin{tabular}{|c|c|c|c|c|c|c|c|c|c|c|}
\hline \multirow{2}{*}{$\begin{array}{l}\text { Optimum } \\
\text { Solution }\end{array}$} & \multirow{2}{*}{$\begin{array}{c}\text { Number of } \\
\text { Interventions }\end{array}$} & \multicolumn{3}{|c|}{$\begin{array}{c}\begin{array}{c}\text { Intervention Times } \\
\text { (years) }\end{array} \\
\end{array}$} & \multicolumn{3}{|c|}{ Intervention Type } & \multirow{2}{*}{$\begin{array}{l}\text { Critical Crack } \\
\text { Size for } \\
\text { Maintenance } \\
(\mathrm{mm})\end{array}$} & \multicolumn{2}{|c|}{ Objective Values } \\
\hline & & $t_{1}$ & $t_{2}$ & $t_{3}$ & Action 1 & Action 2 & Action 3 & & $\begin{array}{c}E[T] \\
\text { (years) }\end{array}$ & $\begin{array}{c}E\left[C_{t o t}\right] \\
(\$ 1000)\end{array}$ \\
\hline A1 & 1 & 19.72 & - & - & Ins & - & - & 5.96 & 28.99 & 28.63 \\
\hline $\mathrm{A} 2$ & 1 & 15.13 & - & - & Ins & - & - & 4.23 & 30.77 & 45.57 \\
\hline A3 & 2 & 16.98 & 34.18 & - & Ins & Ins & - & 4.80 & 39.77 & 77.21 \\
\hline A4 & 3 & 16.53 & 33.72 & 52.41 & Ins & Ins & Ins & 4.52 & 48.50 & 111.02 \\
\hline B1 & 1 & 15.05 & - & - & Mon $^{3}$ & - & - & 5.58 & 30.46 & 55.06 \\
\hline $\mathrm{B} 2$ & 2 & 17.25 & 36.72 & - & Ins & $\operatorname{Mon}^{2}$ & - & 7.29 & 38.46 & 77.04 \\
\hline B3 & 3 & 13.36 & 26.94 & 41.68 & Ins & Ins & $\operatorname{Mon}^{1}$ & 4.10 & 51.58 & 174.00 \\
\hline
\end{tabular}

Ins = Inspection; Mon = Monitoring

Mon ${ }^{1}$ refers to $t_{m d}=$ one day; Mon ${ }^{2}$ refers to $t_{m d}=$ one week; Mon ${ }^{3}$ refers to $t_{m d}=$ six weeks 
Table 2. Design variables and objective function values associated with the optimum solutions shown in Figures 9 and 10

\begin{tabular}{|c|c|c|c|c|c|c|c|c|c|c|c|}
\hline \multirow{2}{*}{$\begin{array}{l}\text { Optimum } \\
\text { Solution }\end{array}$} & \multirow{2}{*}{$\begin{array}{l}\text { Number of } \\
\text { Interventions }\end{array}$} & \multicolumn{3}{|c|}{$\begin{array}{c}\text { Intervention Times } \\
\text { (years) }\end{array}$} & \multicolumn{3}{|c|}{ Intervention Type } & \multirow{2}{*}{$\begin{array}{l}\text { Critical Crack } \\
\text { Size for } \\
\text { Maintenance } \\
(\mathrm{mm})\end{array}$} & \multicolumn{3}{|c|}{ Objective Values } \\
\hline & & $t_{1}$ & $t_{2}$ & $t_{3}$ & $\begin{array}{c}\text { Action } \\
1\end{array}$ & $\begin{array}{l}\text { Action } \\
2\end{array}$ & $\begin{array}{c}\text { Action } \\
3\end{array}$ & & $\begin{array}{c}E[T] \\
\text { (years) }\end{array}$ & $\begin{array}{c}E\left[C_{t o t}\right] \\
(\$ 1000)\end{array}$ & $\begin{array}{c}E[D] \\
\text { (years) }\end{array}$ \\
\hline $\mathrm{C} 1$ & 3 & 19.70 & 20.73 & 25.12 & Ins & Ins & Mon $^{1}$ & 9.86 & - & 112.19 & 18.07 \\
\hline $\mathrm{C} 2$ & 3 & 1.02 & 2.08 & 8.27 & Ins & Ins & Mon $^{1}$ & 6.96 & - & 239.44 & 7.69 \\
\hline $\mathrm{C} 3$ & 3 & 9.92 & 30.87 & 33.87 & Ins & Mon $^{1}$ & Mon $^{1}$ & 3.51 & - & 173.44 & 16.12 \\
\hline $\mathrm{C} 4$ & 3 & 1.26 & 2.27 & 6.39 & Ins & Ins & Ins & 1.86 & & 356.50 & 7.44 \\
\hline D1 & 1 & 6.53 & - & - & Mon $^{3}$ & - & - & 6.20 & 27.34 & - & 13.39 \\
\hline $\mathrm{D} 2$ & 3 & 1.39 & 3.42 & 7.47 & Ins & Ins & Mon $^{3}$ & 7.57 & 28.29 & - & 7.96 \\
\hline D3 & 3 & 10.94 & 23.75 & 38.22 & Ins & $\operatorname{Mon}^{1}$ & $\operatorname{Mon}^{1}$ & 3.17 & 51.17 & - & 17.25 \\
\hline
\end{tabular}

Ins = Inspection; Mon = Monitoring

Mon ${ }^{1}$ refers to $t_{m d}=$ one day; $\operatorname{Mon}^{3}$ refers to $t_{m d}=$ six weeks 
Table 3. Design variables and objective function values associated with the optimum solutions shown in Figure 11

\begin{tabular}{|c|c|c|c|c|c|c|c|c|c|c|c|}
\hline \multirow{2}{*}{$\begin{array}{l}\text { Optimum } \\
\text { Solution }\end{array}$} & \multirow{2}{*}{$\begin{array}{l}\text { Number of } \\
\text { Interventions }\end{array}$} & \multicolumn{3}{|c|}{$\begin{array}{l}\text { Intervention Times } \\
\text { (years) }\end{array}$} & \multicolumn{3}{|c|}{ Intervention Type } & \multirow{2}{*}{$\begin{array}{l}\text { Critical Crack } \\
\text { Size for } \\
\text { Maintenance } \\
(\mathrm{mm})\end{array}$} & \multicolumn{3}{|c|}{ Objective Values } \\
\hline & & $t_{1}$ & $t_{2}$ & $t_{3}$ & Action 1 & Action 2 & Action 3 & & $\begin{array}{c}E[T] \\
\text { (years) }\end{array}$ & $\begin{array}{c}E\left[C_{t o t}\right] \\
(\$ 1000)\end{array}$ & $\begin{array}{c}E[D] \\
\text { (years) }\end{array}$ \\
\hline$\overline{\text { E1 }}$ & 3 & 18.98 & 21.72 & 26.53 & Ins & Ins & $\operatorname{Mon}^{1}$ & 7.60 & 33.05 & 111.12 & 17.75 \\
\hline E2 & 3 & 1.06 & 2.08 & 8.36 & Ins & Ins & $\operatorname{Mon}^{1}$ & 7.10 & 29.09 & 239.60 & 7.47 \\
\hline $\mathrm{F} 1$ & 3 & 12.07 & 25.44 & 39.59 & Ins & $\operatorname{Mon}^{1}$ & Ins & 6.40 & 51.81 & 265.96 & 21.03 \\
\hline $\mathrm{F} 2$ & 3 & 1.04 & 2.23 & 4.10 & Ins & Ins & Ins & 4.26 & 24.86 & 433.50 & 6.47 \\
\hline
\end{tabular}

Ins = Inspection; Mon = Monitoring

Mon ${ }^{1}$ refers to $t_{m d}=$ one day 


\section{Figure Captions}

Figure 1: Crack propagation under uncertainty, PDF of service life, and its CDF with and without repairs

Figure 2: Probability of damage detection with respect to monitoring duration

Figure 3: Event tree model for damage detection and repair, later incorporated in formulating the life-cycle cost, expected service life, and maintenance delay, considering one intervention

Figure 4: Flowchart of the proposed intervention optimization approach

Figure 5: The studied critical location

Figure 6: Results of the Monte Carlo simulation: (a) histogram of the initial service life, and (b) PDF and CDF of the initial service life of the studied detail

Figure 7: Pareto-optimal solutions for minimizing the expected total life-cycle cost, and maximizing the expected service life for one, two, and three scheduled interventions

Figure 8: Optimization solution for minimizing the expected total life-cycle cost, and maximizing the expected service life; (a) Pareto-optimal solutions for different inspection costs, and (b) details of three representative solutions B1, B2, and B3

Figure 9: Pareto-optimal solutions for minimizing the expected maintenance delay and minimizing the life-cycle cost for three scheduled interventions and different failure costs

Figure 10: Pareto-optimal solutions for minimizing the expected maintenance delay and maximizing the expected service life for one and three scheduled interventions

Figure 11: Pareto-optimal solutions of the tri-objective optimization problem with different failure costs $C_{f}$

Figure 12: Effect of the failure $\operatorname{cost} C_{f}$ on the average probability of repair and the average probability of failure of optimum solutions 

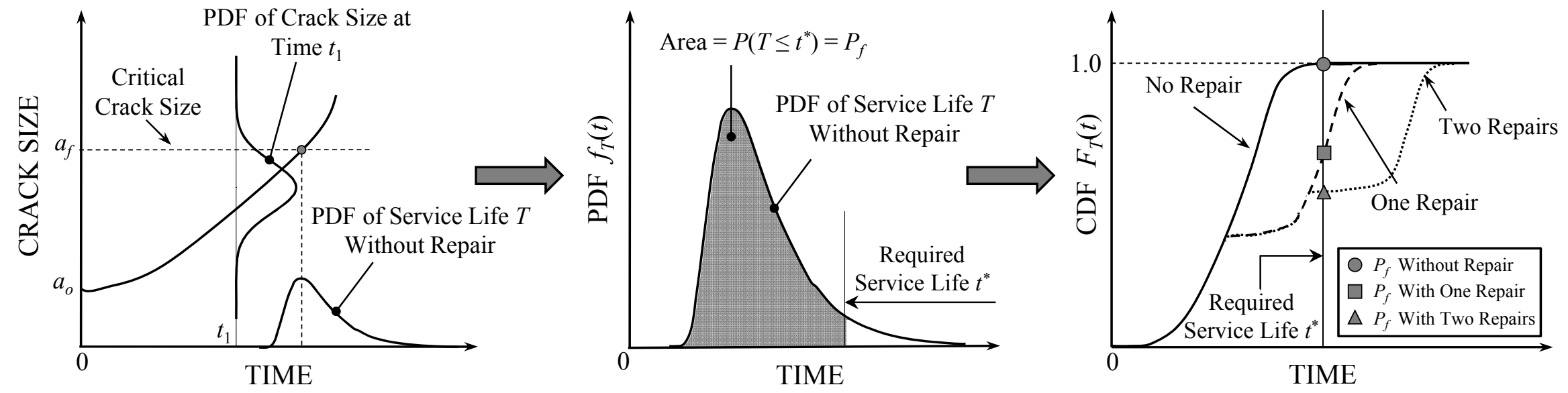

Figure 1 


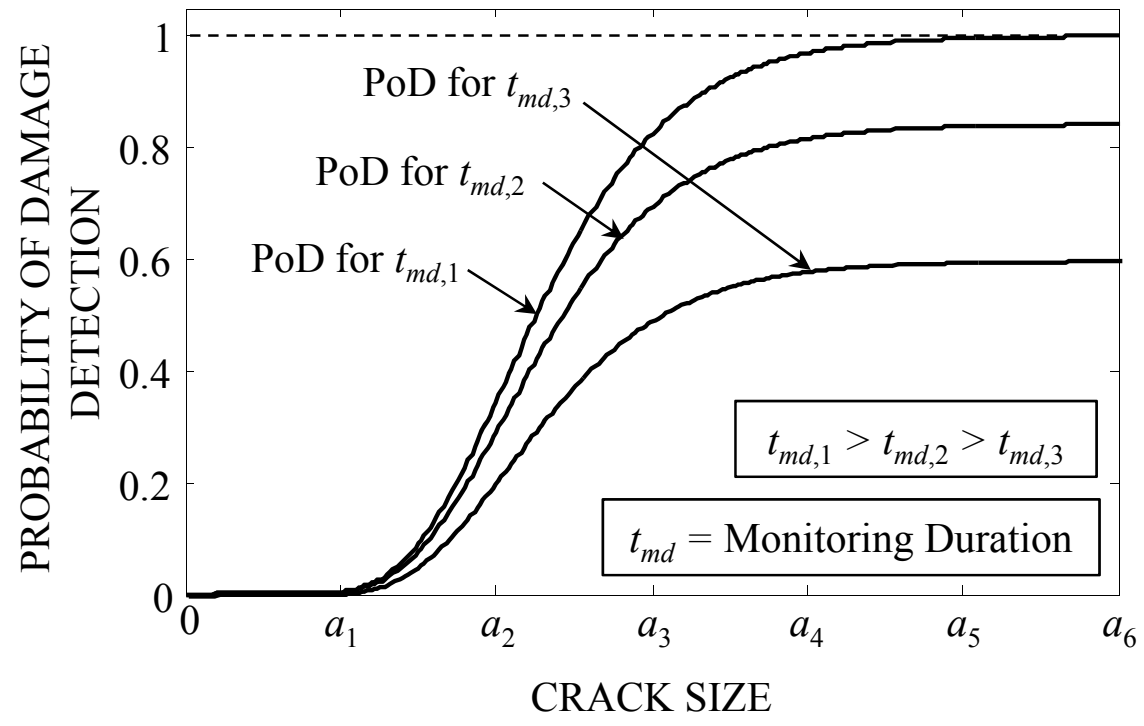

Figure 2 


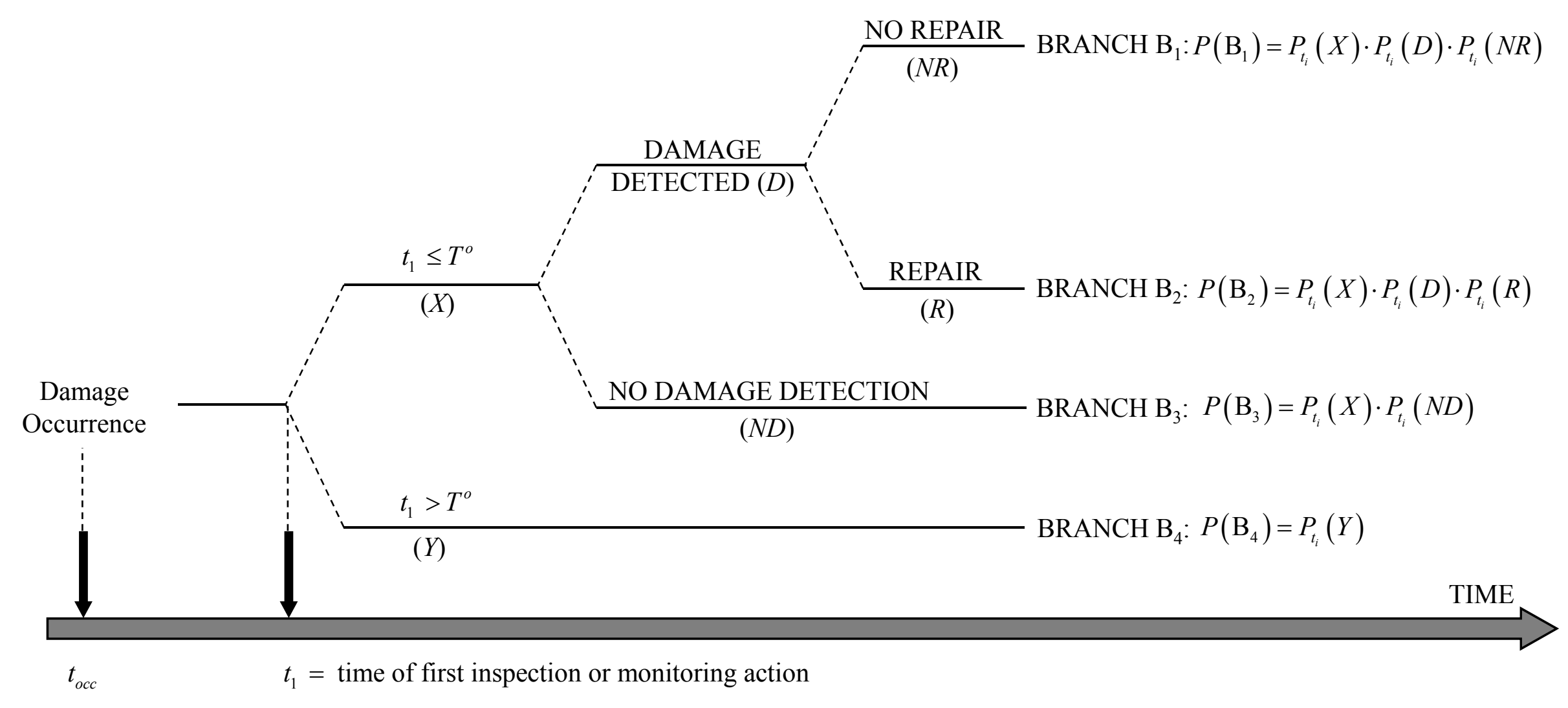

Figure 3 


\section{START}

$\downarrow$

INPUT

- Fatigue crack model and associated parameters

- Inspection method information including probability of detection ( $\mathrm{PoD})$ and cost

- Monitoring information including probability of detection (PoD) and cost

- Number of interventions and maintenance cost

- Failure size of crack

- Discount rate of money

- Number of samples

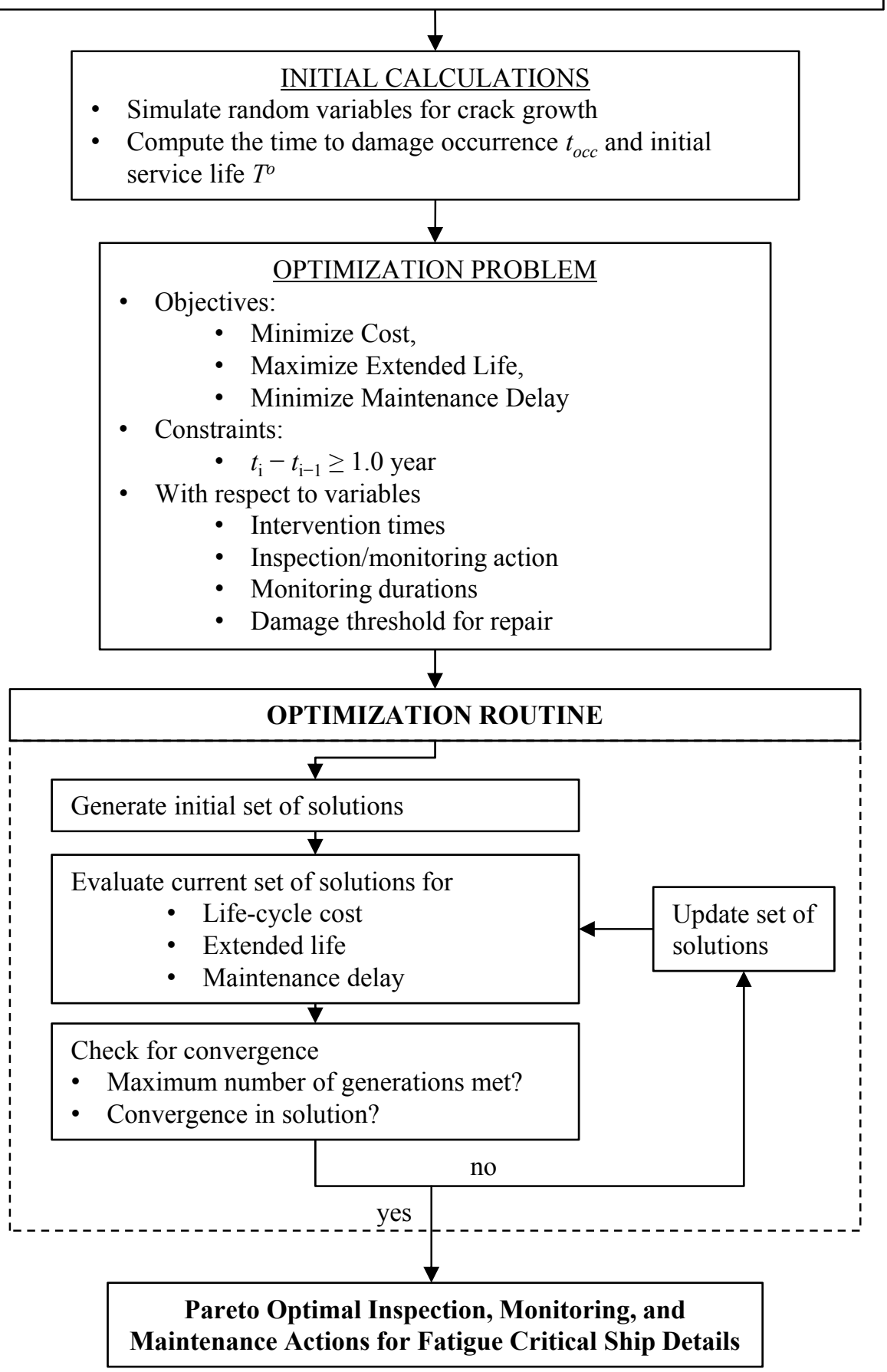

Figure 4 


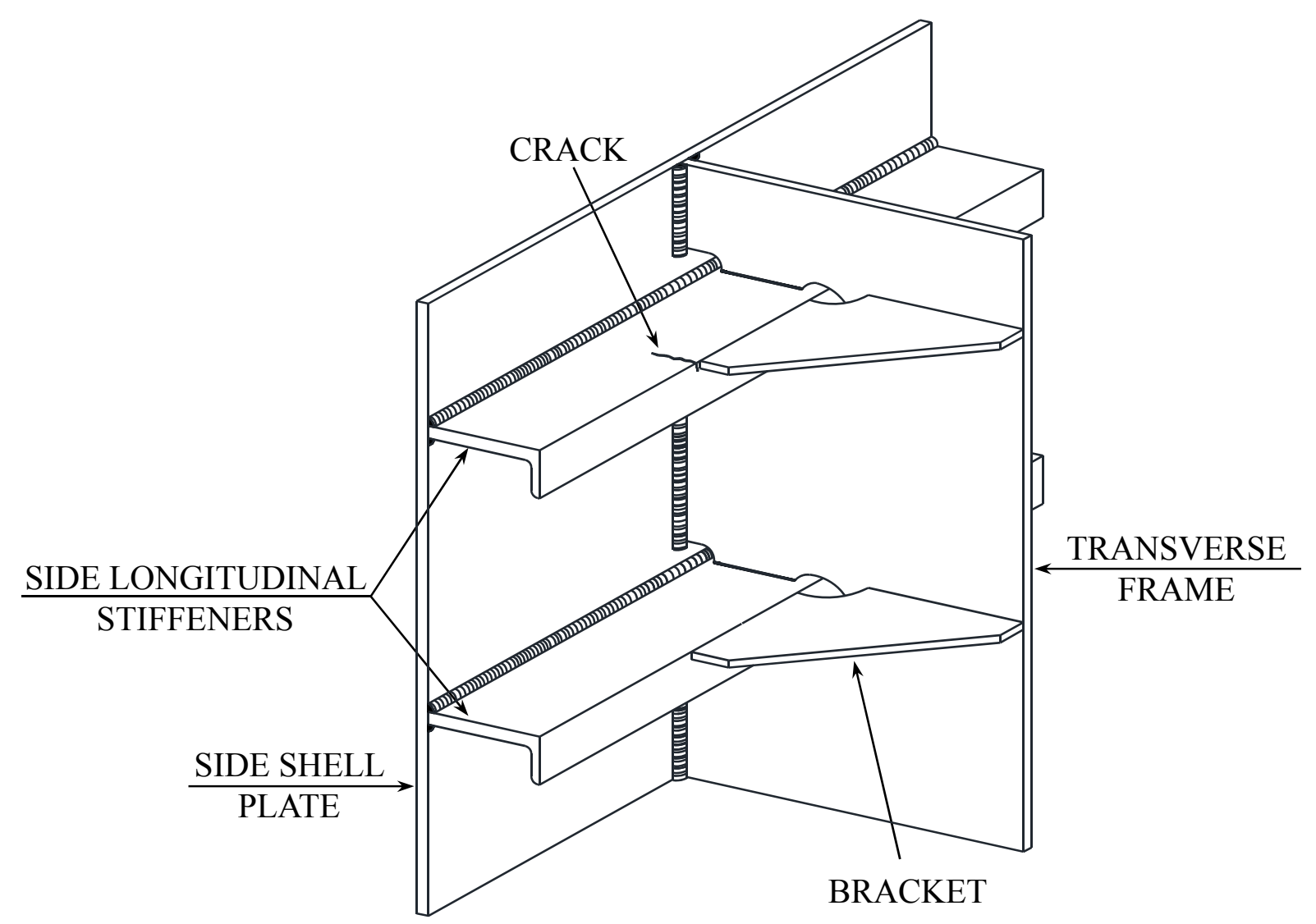

Figure 5

\author{
Figure 5
}


(a)

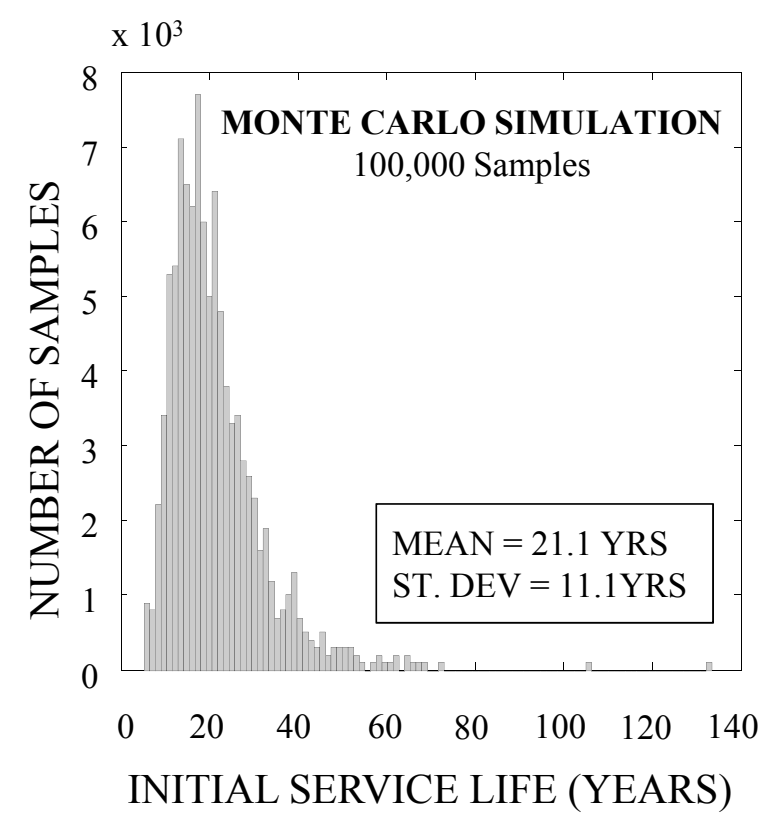

(b)

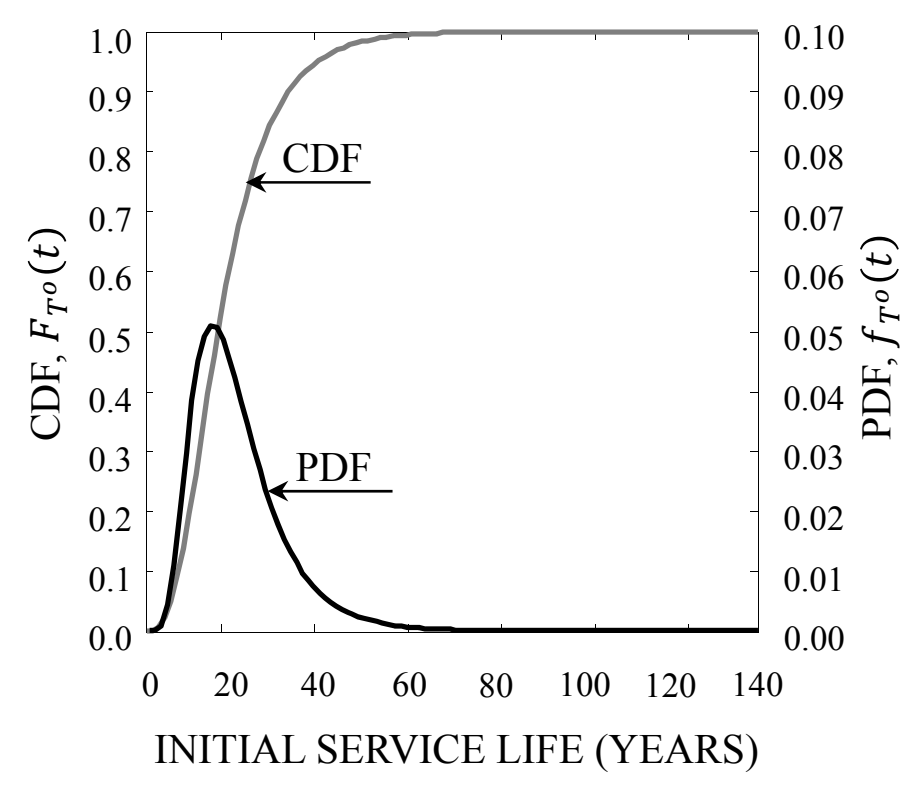

Figure 6 


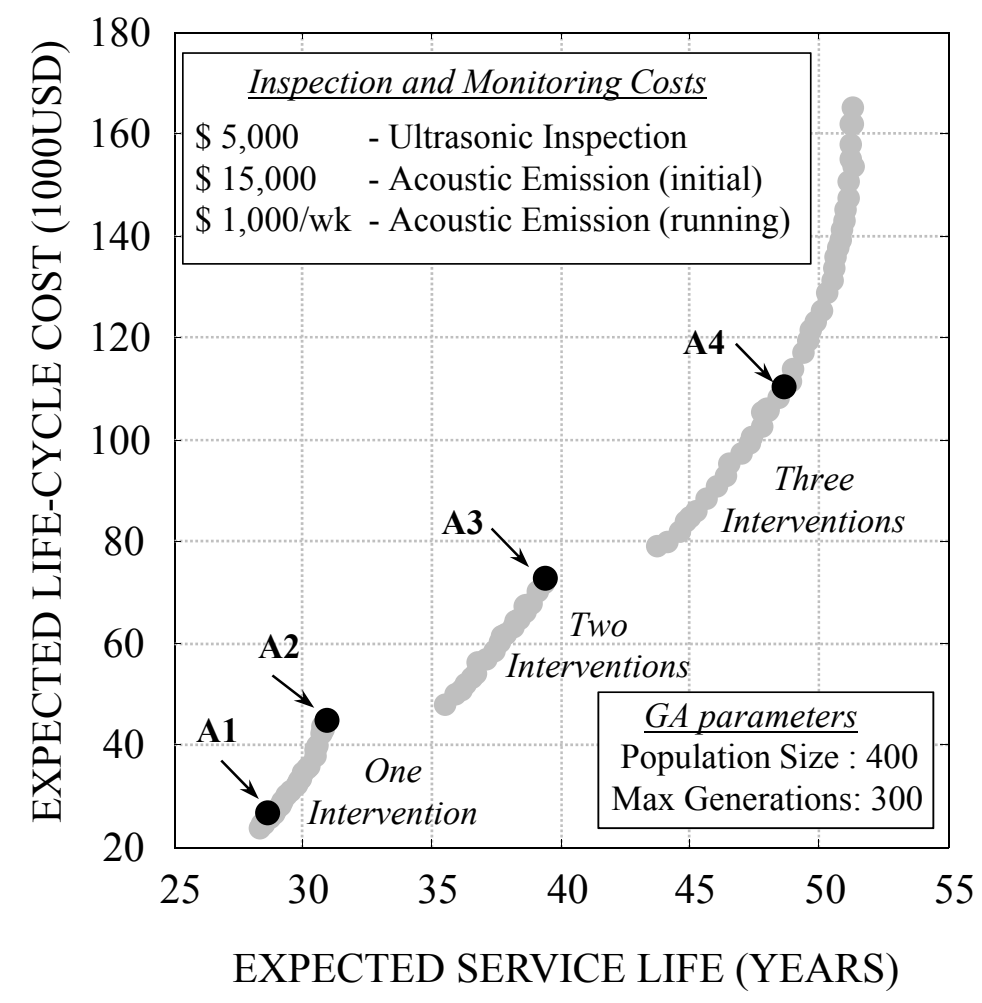

Figure 7 
(a)

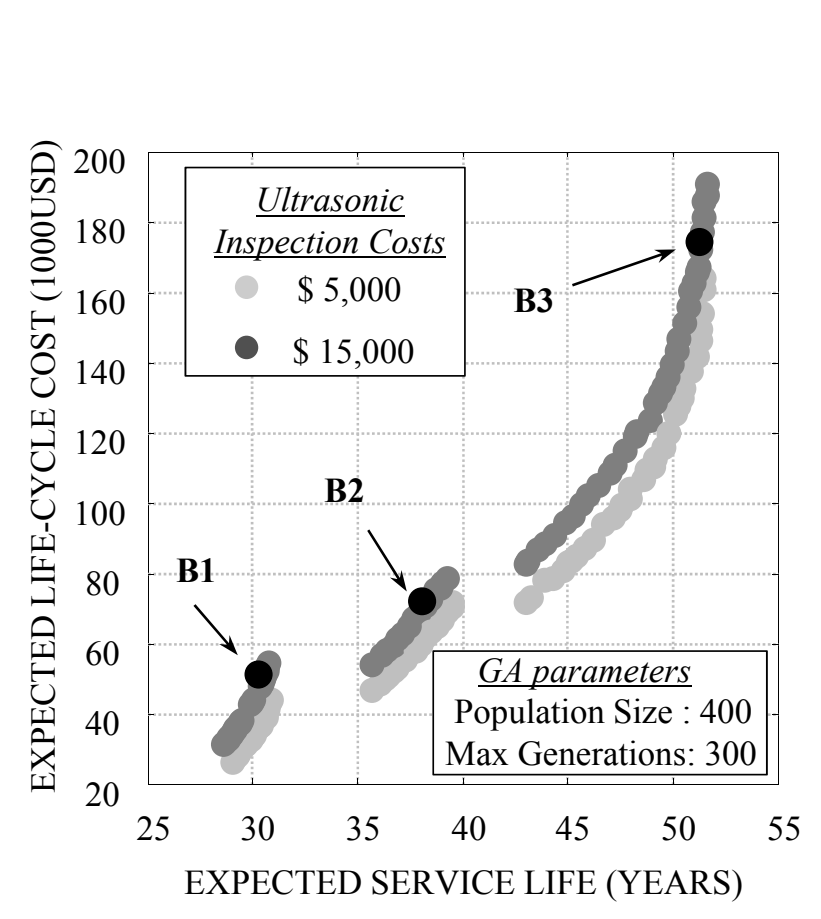

(b)

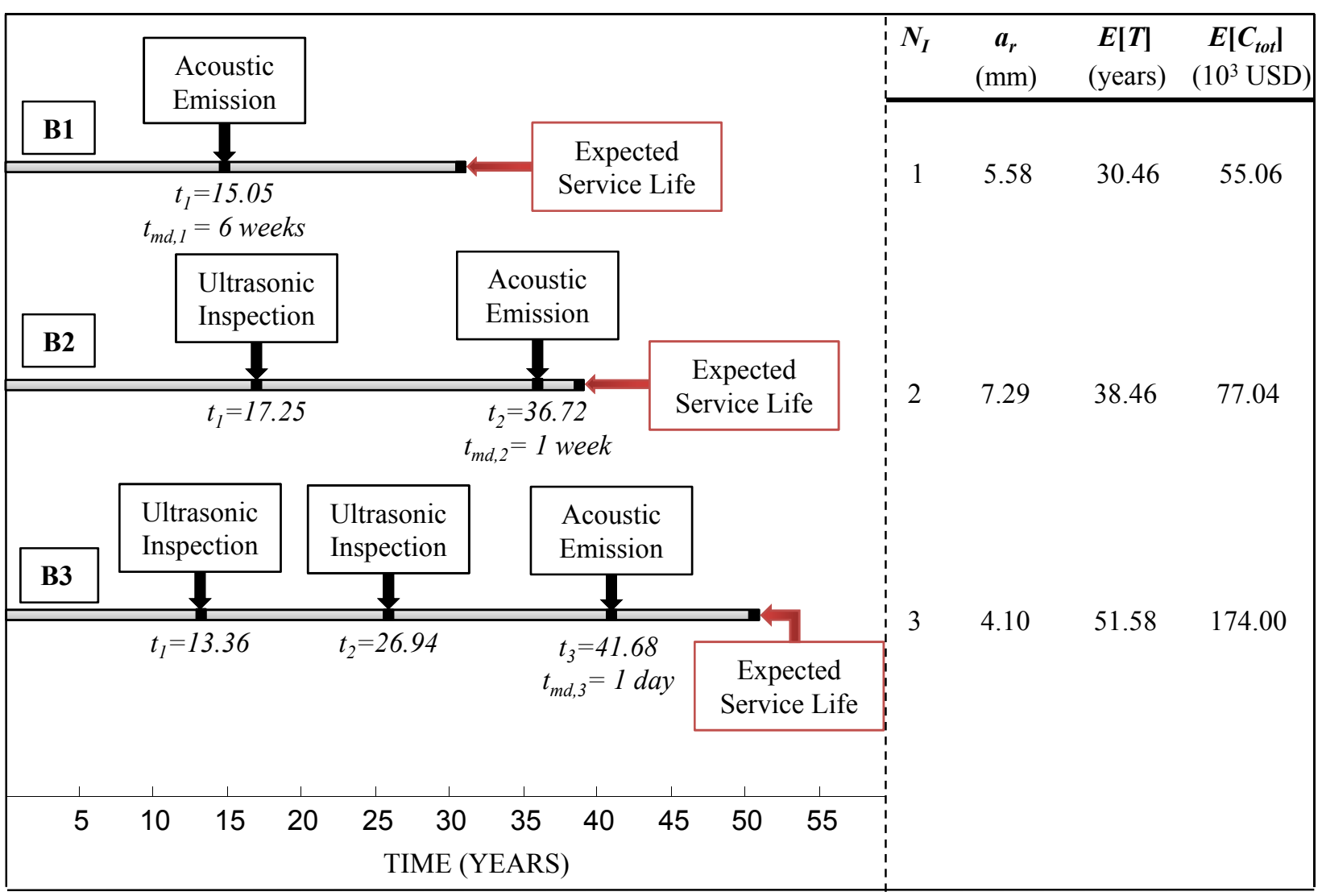

Figure 8 


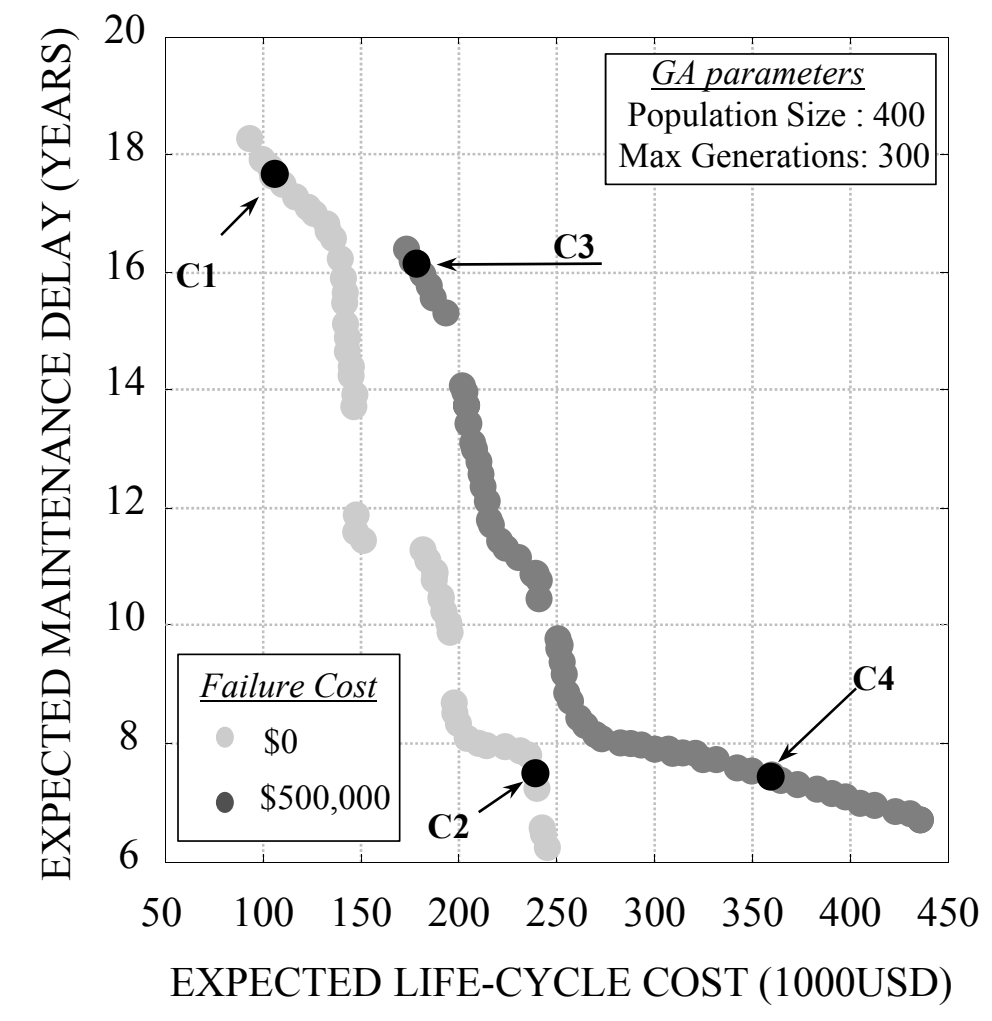

Figure 9 


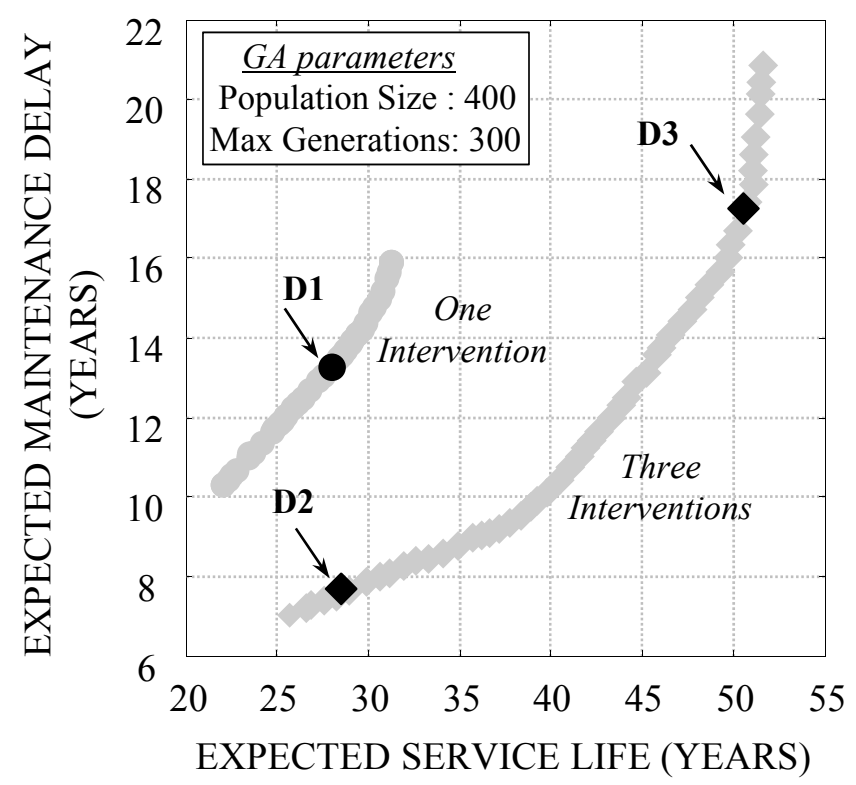

Figure 10 


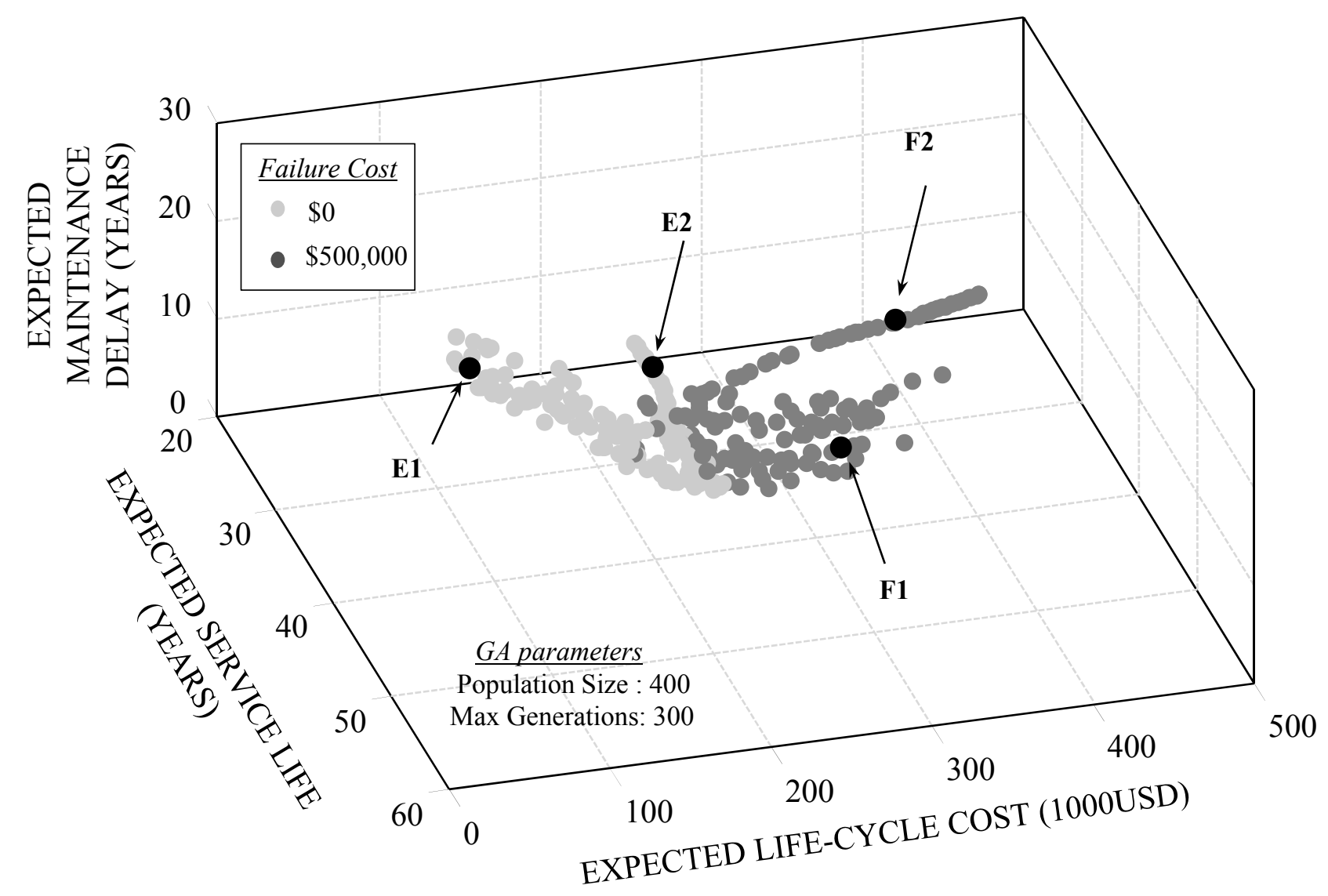

Figure 11 


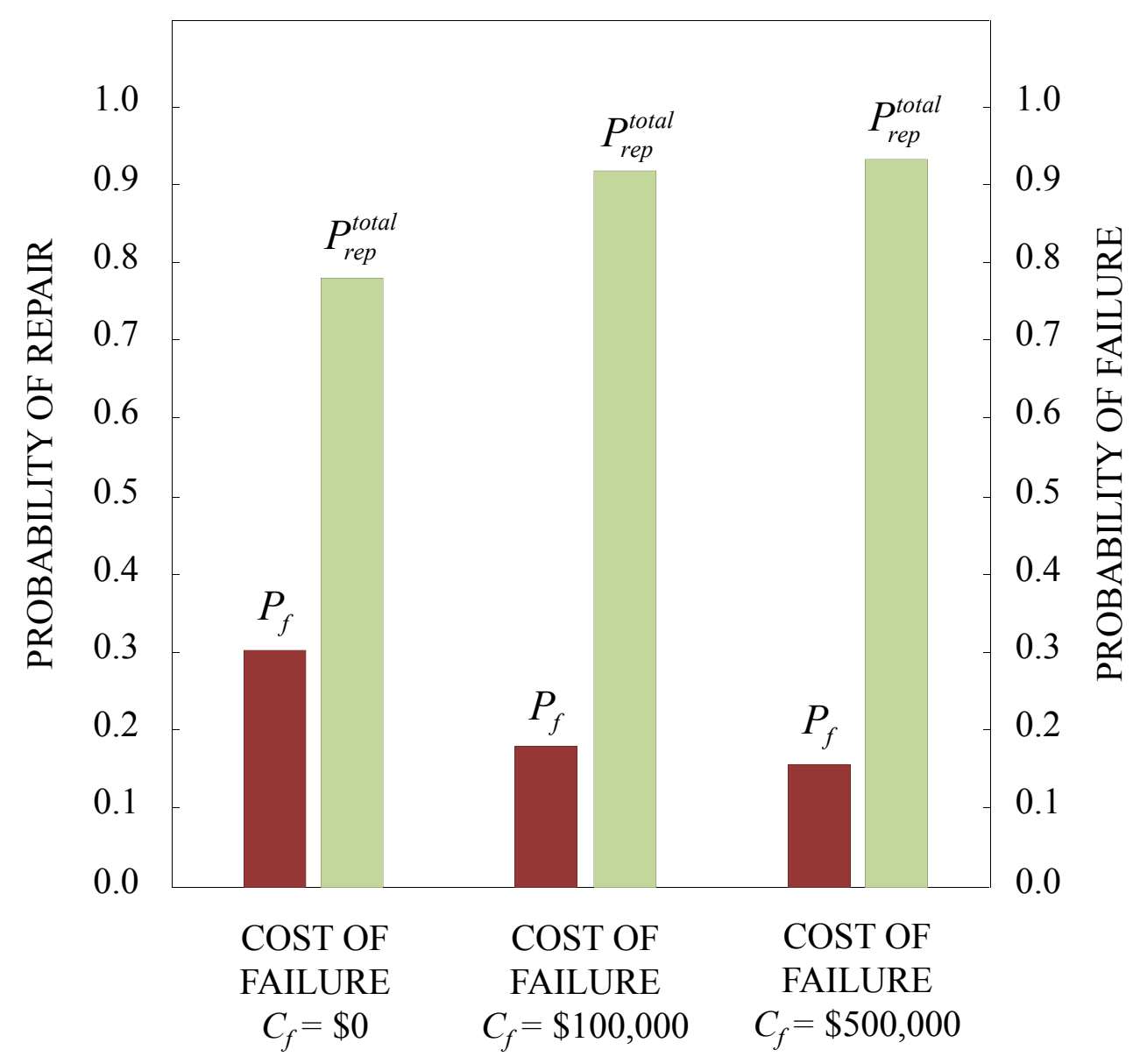

Figure 12 